THE UNIVERSITY OF ARIZONA

INSTITUTE OF ATMOSPHERIC PHYSICS

SCIENTIFIC REPORT NO. 28

DOPPLER RADAR OBSERVATIONS OF A HAILSTORM

Louis J. Battan

Institute of Atmospheric Physics

Tucson, Arizona

1 February 1974

\author{
Research supported by the \\ Atmospheric Sciences Section, \\ National Science Foundation, \\ NSF Grant GA-37825X
}




\title{
DOPPLER RADAR OBSERVATIONS OF A HAILSTORM ${ }^{1}$
}

\author{
Louis J. Battan \\ Institute of Atmospheric Physics \\ University of Arizona \\ Tucson, Arizona 85721
}

\begin{abstract}
$\underline{\text { ABSTRACT }}$
A severe hailstorm, occurring on 10 August 1966, passed over a zenith pointing, $\mathrm{x}$-band, pulsed-Doppler radar located on a mountain in southeastern Arizona. An analysis was made of measurements of radar reflectivity, mean Doppler velocity, variance of the Doppler spectrum and calculated updraft velocity. The vertical air motions and characteristics of the hydrometeors within the storm were highly variable over distances of a few hundred meters to a few kilometers. The storm consisted of a series of updraft cores containing a number of discrete volumes, 1 to $2 \mathrm{~km}$ in diameter, of rapidly rising air with smaller accompanying eddies. The updraft cores were separated by regions of weak updrafts or downdrafts. For the most part, the highest reflectivitives were outside the updraft cores. It is visualized that the hailstone growth was initiated within the updraft, not as a continuous process, but rather as pockets of hailstones within the fast rising distinct volumes. This process could account for the layers of clear and opaque ice within large stones by allowing them to pass through several rising volumes. It might also account for brief bursts of hail and short hailstreaks observed at the ground.
\end{abstract}

\footnotetext{
lThis research has been supported by the Atmospheric Sciences Section of the National Science Foundation under grants GA-24134 and $\mathrm{GA}-37825 \mathrm{X}$
} 
DOPPLER RADAR OBSERVATIONS OF A HAILSTORM

\author{
Louis J. Battan \\ Institute of Atmospheric Physics \\ University of Arizona \\ Tucson, Arizona 85721
}

The internal structure of thunderstorms has been a subject of long standing interest, especially in the case of severe storms capable of producing large hail (Ludlam, 1963). The hazards posed by hail and turbulence has discouraged, but has not prevented, the measurements inside such storms by means of aircraft. Observations of air motions under and around hailstorms have been made with airplanes (Marwitz, 1972). Sinclair (1973) and others have measured updraft speeds and turbulence in the upper parts of severe thunderstorms. Recently, a few penetrations through hailstorms have been made with a specially "armored airplane" (Musil, et al., 1973) .

Some measurements of the air motions within hailstorms have been obtained by tracking balloons (Sulakvelidze, et al., 1965) or chaff (Marwitz, 1972, 1973) carried into the storms. Bushnell (1973) measured the initial air motions in a thunderstorm by means of devices dropped through it.

Much of what we know about the structure of hailstorms has come from the analysis of radar observations (e.g., Browning, 1963; Browning and Ludlam, 1962; Sulakvelidze, et al., 1965; Marwitz, 1972; Dennis and Musil, 1973; Foote and Fankhauser, 1973). From a study of the characteristics of the radar echoes and their changes with time, physical models have been constructed in an 
attempt to explain the properties of hailstones observed falling to the ground.

In order to improve numerical models of hailstorms such as those developed by Danielson, et al. (1972) and Wisner, et al. (1972), more detailed observations of the updraft structure and hydrometeors in the storms are needed. This paper shows that in some circumstances, when a severe hailstorm passes over a suitable Doppler radar, it is possible to measure the internal structure of the storm in considerable detail.

\section{Equipment}

The data presented in this article were obtained by means of an $\mathrm{X}$-band pulsed Doppler radar described in earlier papers. In one of them, Battan and Theiss (1972) attempted to derive a hailsize spectra from observed Doppler-spectrum measurements. The radar set was located at an elevation of $2,800 \mathrm{~m}$ on the summit of Mount Lemmon which is just northeast of Tucson, Arizona. All the Doppler radar observations were made with the antenna pointing towards the zenith. At intervals of about $47 \mathrm{sec}$, measurements of various quantities were obtained at height intervals of $152 \mathrm{~m}$ between about $500 \mathrm{~m}$ and $11 \mathrm{~km}$ above the ground. At each altitude, the radar yielded the complete Doppler spectrum as well as the total backscattered power averaged over about 0.66 sec. $^{2}$

${ }^{2}$ In this analysis an upwards velocity is taken to be positive. 
Calculations were made of the effective reflectivity factor $\mathrm{Z}$, the mean Doppler velocity $\bar{V}$, the velocity variance of the spectrum $\sigma_{\mathrm{v}}{ }^{2}$, and a quantity called the Rogers' updraft velocity $\mathrm{W}_{\mathrm{R}}$. It is an estimate of the updraft velocity obtained by adding $\bar{V}$ and a quantity $\overline{\mathrm{W}}_{\mathrm{T}}$ which is an estimate of the mean Doppler velocity in still air of raindrops yielding the same $\mathrm{Z}$ as the one observed. In this analysis we employed the equation $\overline{\mathrm{W}}_{\mathrm{T}}=+3.8 \mathrm{z} 0.072$ derived by Rogers (1964). It is recognized that in the case of hail this expression is not strictly applicable because the appropriate $\overline{\mathrm{W}}_{\mathrm{T}}$ versus $\mathrm{Z}$ equation will be different than the one given by Rogers (1964). Unfortunately, in the case of hail there is no single, applicable equation because the fall velocities and scattering cross sections of hailstones depend on the particle compositions, shapes, and in some cases, surface roughnesses, as well as diameters. Another complicating factor is that limited available data indicates that the size-distribution of hail often deviates markedly from an exponential one.

It would be expected that in regions of very high reflectivities, hailstones are likely to be present, and Rogers' equation would underestimate $\bar{W}_{T}$ because the terminal velocities of hailstones can substantially exceed those of raindrops. In an earlier paper, Battan and Theiss (1972) estimated that in one situation where maximum hail diameters were about $2.5 \mathrm{~cm}$, Rogers' equation yielded downdraft speeds having errors of about $2 \mathrm{~m} \mathrm{sec}^{-1}$.

\section{First set of observations}

The hailstorm discussed in this article occurred on 10 August 1966. Thunderstorms developed and moved overhead in the early 
afternoon. Light, intermittent rain started at about 1330 MST. The first hailstones, observed at 1451 MST, were small, having diameters of about $5 \mathrm{~mm}$. Intermittent showers of hail of varying sizes and intensities continued until at least 1705 MST. At times, hailstone diameters were as large as $25 \mathrm{~mm}$. Near the radar set, accumulated hail on the ground reached a depth of more than $5 \mathrm{~cm}$. The data to be presented here extends over two periods, 1500-1512 MST and 1546-1606 MST, during which times the character of the precipitation changed rapidly from rain early in the period to large hail at the end. The weather observed and recorded at the radar during the first period of observations is given in Table 1 . Figures la-d display the properties of the storm observed overhead during the period 1500-1512 MST. Along the right hand side of Figure lc are wind velocities obtained by the radiosonde released by National Weather Service personnel at about 1615 MST from a point about $40 \mathrm{~km}$ from the radar. Figure 2 also gives wind velocities as well as temperature and dew point profiles. The distance scale shown along the upper horizontal scales in Figure 1 was obtained by multiplying elapsed time by $8.2 \mathrm{~m} \mathrm{sec}^{-1}$ which is a mean wind speed through the cloud layer. The cloud base was variable ranging between altitudes estimated between 2.7 to $2.9 \mathrm{~km} \mathrm{MSL}$. This put it just below to just above the elevation of the radar and about $2 \mathrm{~km}$ above the floor of the valley from which the radiosonde was released.

The depiction of time and distance scales along the abscissa is a reminder of the difficulties in interpreting the data from a single, zenith-pointing radar which is observing a rapidly changing storm. It is not possible to discriminate satisfactorily 
Table 1. Weather Observations at Radar During the Period of Analysis.

\begin{tabular}{|c|c|}
\hline $\begin{array}{l}\text { TIME } \\
\text { (MST) }\end{array}$ & OBSERVATION \\
\hline 1459 & Close thunder; rain steady. \\
\hline 1500 & Echo up to $35,000 \mathrm{ft}$. \\
\hline 1503 & Trace of hail -- about 1/4" but in small numbers. \\
\hline 1505 & $\begin{array}{l}\text { Intensity of hail picking up; updrafts; clouds } \\
\text { are low and visibility poor. }\end{array}$ \\
\hline 1506 & Hail heavy now with sizes up to $3 / 8 "$. \\
\hline 1506.5 & Hail size now includes a few $1 / 2 "$, ground covered. \\
\hline 1508 & Hail to $3 / 4 "$; very close lightning. \\
\hline 1509 & $\begin{array}{l}\text { Hail to } 1 \text { " in size, very heavy and intense; sounds } \\
\text { like a popcorn popper here in van. }\end{array}$ \\
\hline 1513 & Hail not so hard; sizes about $1 / 2 "$. \\
\hline
\end{tabular}


between space and time changes. A single, vertical set of observations was made over such a short period of time, that differences from one altitude to the next can be regarded as spacial differences. On the other hand changes from one observation to the next at the same altitude are more difficult to interpret. When a certain characteristic maintains itself over a several minute period, it can be speculated that the time changes were relatively slow.

In interpreting height-time observations, you must also recognize that the cross section need not be through the center of the storm. Also it is necessary to recognize that air and hydrometeors probably have motions perpendicular to the plane of observation to degrees which vary with time and altitude.

Notwithstanding the difficulties, it still is possible to learn something about the structure of hailstorms from these observations.

Figure la shows the pattern of radar reflectivity factor. As would be expected in a storm producing hailstones up to $25 \mathrm{~mm}$ in diameter, $\log \mathrm{z}$ exceeded 5.0 . It should be noted that the topography of the upper part of the echo was determined in part by attenuation caused by highly reflective particles. The pronounced dip at about 1505 MST was associated with the high reflectivity region at altitudes between about 5.5 and $7.5 \mathrm{~km}$. Also towards the end of the period, particularly after about 1510 MST, the pronounced fall of the top of the detectable echo was associated with the region of very high reflectivity. 
Figures $1 \mathrm{~b}$ and $1 \mathrm{c}$ show the patterns of observed mean Doppler velocity and of calculated "updraft velocity" respectively. It is clear from the former that in the upper parts of the cloud there were updrafts which certainly exceeded maxima of $18 \mathrm{~m} \mathrm{sec} \mathrm{sec}^{-1}$. Assuming that the hydrometeors were raindrops and taking their fall velocities into account, Rogers' equation yields the velocities given in Figure 1c. In the presence of hail it is likely that the correction for the fall velocity of the hydrometeors was too small. On this ground, it seems reasonable to view the updrafts in Figure lc as being underestimated while the downdrafts are overestimated.

Figure 1 shows that the internal structure of this hailstorm was highly variable with very large differences in reflectivity and air velocity over distances of several hundred meters. Airplane traverses through severe thunderstorms (e.g., Sinclair, 1973; Musil, et al., 1973) and dropsonde observations also reveal such variabilities. As has been noted by others who have made Doppler radar observations, the updrafts occurred mostly in the upper parts of the thunderstorm. In this case there were two updraft cores, which would have been separated by a distance of about $2 \mathrm{~km}$ if the storm actually passed overhead at a mean speed of $8.2 \mathrm{~m} \mathrm{sec}^{-1}$. The pattern of updrafts resembles fairly large rising buoyant plumes or bubbles separated by regions of slowly rising or sinking air.

The lower part of the storm was dominated by downdrafts which were weaker than about $4 \mathrm{~m} \mathrm{sec}^{-1}$ before about $1506 \mathrm{MST}$ and reached 8 to $10 \mathrm{~m} \mathrm{sec}^{-1}$ towards the end of the period. 
If it continues to be assumed that the storm was moving with the wind, it can be visualized that the air entered the storm on the southeastern side and followed the path depicted by the dashed lines. Deep echo-free vaults of the type reported by Browning and Ludlam (1962) and Browning (1965) are not evident, but at the lower end of the main updraft core there appears to be a small weakecho vault such as those reported by Marwitz (1972) and others. Figure ld shows the pattern of the variance of the Doppler spectra. It is known that the calculated variances of observed spectra depend to a certain extent on the definition of the noise level (Donaldson, et al., 1972). In this analysis it was determined subjectively by examining the spectral data and selecting the level at the tails of the spectra below which there appeared to be random signals or signals which were clearly in the noise level of the spectrum analyzer. A more objective technique such as the one developed by Hildebrand and Sekhon (1973) would be an improvement over the scheme we used. At any rate, although the measured variances, particularly the larger ones, may be substantially in error, the ones depicted clearly extend over a large range indicating large variations in the size of the hydrometeors even when allowances of a few meters squared per second squared are made for spreading of the Doppler spectra by turbulence and wind shear.

It is particularly interesting to note that along the dashed lines depicting the updraft cores, the variances were relatively small. Outside the updraft, they were quite large, particularly between the two updraft cores depicted on the drawings. One can visualize the start of ice particle growth in 
the strong, tilted updraft with the particles falling out in the manner proposed by Browning and Ludlam (1962). In this storm it can further be imagined that some hailstones fell into the second major updraft. Further growth and fallout could have occurred accounting for the regions of high echo intensity where $\log z>4.7$.

Boston and Rogers (1969) calculated values of $\sigma_{\mathrm{v}}{ }^{2}$ distributions of "wet" and dry ice spheres as a function of maximum diameters. In a private communication, R. R. Rogers informed us that a "wet" sphere was taken to be one composed entirely of water. Figure 3 shows similar calculations of the same hail size distribution but for ice spheres coated with layers of water 0.1 and $0.5 \mathrm{~mm}$ thick. ${ }^{3}$ on the basis of these curves, certain inferences can be ${ }^{3}$ Part of a series of calculations to be reported at a later date by Brooks E. Martner, a graduate student at the University of Arizona.

drawn about the hydrometeors in this storm.

It appears that in the upper parts of the storm, between the updraft cores, there were large hailstones present. Assuming that the variance attributable to size differences is about $15 \mathrm{~m}^{2} \mathrm{sec}^{-2}$ the hydrometeors scattered as if they were ice spheres which were exponentially distributed and had maximum diameters of about $2.5 \mathrm{~cm}$. As shown in Figure 2, cloud temperatures at 9 and $11 \mathrm{~km}$, the levels of variance maxima, were -32 and $-46 \mathrm{C}$. Surely, at the latter temperature, if hail were present it would have been dry, and the 
same was probably true at the $-32 \mathrm{C}$ level also.

The variance maximum centered at about $6.8 \mathrm{~km}$ at about 1502 MST presumably also indicates the presence of dry hail having maximum diameters approaching $3 \mathrm{~cm}$. The temperature in this region was about $-15 \mathrm{C}$, warm enough for supercooled hydrometeors to be present. On the other hand if the particles were carried down from higher and colder elevations, at the observed mean velocities of 6 to $10 \mathrm{~m} \mathrm{sec}^{-1}$, they could have arrived at the indicated altitudes in a dry state.

The variance maxima of about $14 \mathrm{~m}^{2} \mathrm{sec}^{-2}$ at altitudes below $5.3 \mathrm{~km}$, the level of $0 \mathrm{C}$, at about $1504 \mathrm{MST}$ are difficult to explain because melting and the development of a layer of water would reduce the variance (Figure 3 ). The distance from the $0 \mathrm{C}$ isotherm to the lower limit of the $\sigma_{\mathrm{v}}{ }^{2}=10$ contour at about 1504 MST was about $1,100 \mathrm{~m}$. The mean Doppler velocity, at this time (Figure 1b), between the altitudes involved averaged $9 \mathrm{~m} \mathrm{sec}{ }^{-1}$. Therefore, the time for the hailstones to $1,100 \mathrm{~m}$ was $2.0 \mathrm{~min}$. Nearly the entire hailstone must be warmed to nearly $0 \mathrm{C}$ before melting of the outer layer begins (Atlas, et al., 1960).

In the case of fast falling hailstones 2 to $3 \mathrm{~cm}$ in diameter, coming from very cold altitudes, it seems possible the stones can reach a kilometer or so below the $0 \mathrm{C}$ before melting starts. Atlas, et al., (1960) produced ice spheres at temperatures between -30 and $-60 \mathrm{C}$, and found that after being brought into the open air (during the Summer of 1959 near London, England) the ice spheres persisted without melting for periods up to about $15 \mathrm{~min}$. At fall speeds of $9 \mathrm{~m} \mathrm{sec}^{-1}$ the time required for the particles to fall 
from the $-30 \mathrm{C}$ (about $9 \mathrm{~km}$ ) level to $4.5 \mathrm{~km}$ would have been about $8.4 \mathrm{~min}$. It seems possible, therefore, that the particles producing the variance values of 10 to $14 \mathrm{~m}^{2} \mathrm{sec}^{-2}$ were dry hailstones having diameters greater than $2 \mathrm{~cm}$.

Since hail of the sizes shown along the bottom of the diagrams was observed at the radar (at an altitude of $2.8 \mathrm{~km}$ ), the values of $\mathrm{Z}$ and $\sigma_{\mathrm{V}}{ }^{2}$ measured about a minute earlier at $3.5 \mathrm{~km}$ can be associated with the hailstones and possibly rain at some periods. At the observed value of $\bar{V}$ (Figure $1 \mathrm{~b}$ ) of about $14 \mathrm{~m} \mathrm{sec}^{-1}$, the hydrometeors would fall $700 \mathrm{~m}$ in about $50 \mathrm{sec}$. The hail continued at the ground for many minutes. The low values of the variance of 6 to $10 \mathrm{~m}^{2} \mathrm{sec}^{-1}$ corresponds to quantities which can be caused by wet ice spheres having diameters greater than about $2 \mathrm{~cm}$ (Figure 3 ). The high values of $Z$ thus can be attributed to the presence of large, wet hailstones.

\section{Second set of observations}

The second set of radar observations to be discussed were taken during the period 1546 to 1606 MST. The character of the precipitation and other weather at the radar are given in Table 2 . At the beginning of the period there was no precipitation at all. There was a brief shower of small hail and light rain from about 1553 to 1555 MST. Violent weather with much lightning, strong winds and large hail started at about 1600 MST and extended to the end of the period.

The radar observations are depicted in Figures $4 a-d$. It can be seen in Figure 4 a that the largest reflectivities were 
Table 2. Weather Observations at Radar Before and During the Second Period of Analysis.

1514 Hail now about $1 / 4 "$ size and not as heavy - light now.

1517 Hail stopped. Very light drizzle. Hail picked off ground (after hail had stopped and stones were melting) measured $3 / 4 "(1.9 \mathrm{~cm})$.

1520 Air temperature $13 \mathrm{C}$.

1522 Rain stopped.

1538 Ground level clouds moving rapidly NW. Visibility such that can't tell anything about clouds above - a solid blanket of gray. Dark here at site.

1553 Hailing again but no rain - distant lightning. Hail is light and less than $1 / 4 "(0.6 \mathrm{~cm})$.

1555 Raining now. Same intensity hail but some range up to $3 / 8$ " $(1.0 \mathrm{~cm})$.

1557 No hail now.

1559.5 Lightning hit building next door.

1600 Hail - moderate heavy with sizes about $1 / 4 "(0.6 \mathrm{~cm})$.

1603 Hail intensity picking up with sizes to $1 / 2 "(1.2 \mathrm{~cm})$ Frequent very close lightning.

1606 Hail, blowing strong - very strong, under very heavy winds out of the SW. Hail averages l" $(2.5 \mathrm{~cm})$ in size with some larger.

1607 Ground covered.

1609 Radar on blink.

1617 Hail several inches thick on the ground. 
observed in the lower part of the storm near the end of the period and were associated with the fall of large hail.. The lowering of the top of the echo during this time can be attributed, at least in part, to the effects of attenuation.

As was the case in Figure 1, a striking feature of the data in Figure 4 is the highly variable nature of the pattern. There are large changes of $\mathrm{Z}, \mathrm{W}_{\mathrm{R}}, \overline{\mathrm{V}}$ and $\sigma_{\mathrm{V}}{ }^{2}$ over distances of several hundred meters. At the same time the variations are not random in character. In Figure $4 \mathrm{a}$, the most prominent feature is the region of high echo intensity $(\log \mathrm{Z} \geq 4.0)$ extending from an altitude of $10 \mathrm{~km}$ at about $1558 \mathrm{MST}$ to just over the radar at the end of the record. On the basis of the low level pattern after 1600 MST, you might visualize hailstones falling in the plane of observation and reaching the ground as shown at the bottom of the drawing. As will be noted later, velocity and variance data do not support such a simple explanation.

The pattern of echo intensity shows at least two other regions of high echo intensity oriented almost vertically in this heighttime plot. The one at about 1555 MST is poorly defined but undoubtedly exists. Another region of higher echo intensity is clearly evident at about 1551 MST.

As was the case in the first period of observation, the updraft regions in this storm (Figures $4 \mathrm{~b}$ and $\mathrm{c}$ ) did not, in general, coincide with the regions of highest echo intensity. The strongest updraft core observed between 1547 and 1551 MST was in a series of "bubbles" entering the cloud from the southeast and following an initially tilted path upwards through the storm. The updraft, 
in this instance, appears to have been composed of three major ascending bubbles about 1 to $2 \mathrm{~km}$ in diameter with smaller eddies a few hundreds of meters in diameter. This updraft region was associated with a weak echo region at its lower end where it entered the cloud. The ascent of the echo top to an altitude of about $12 \mathrm{~km}$ can be attributed to this strong updraft. Within this updraft core, peak velocities were greater than $12 \mathrm{~m} \mathrm{sec}^{-1}$ (Figure 4b) and estimated to exceed $20 \mathrm{~m} \mathrm{sec}^{-1}$ (Figure 4c).

At about 1551 MST, there were mostly downdrafts and weak updrafts in the region just southwest of the major updraft. The echo intensity was fairly high with $\log z$ reach 4.5 . Below this region and a few minutes later (1553 to 1555 MST) there was a shower of small hailstones.

Examination of Figure $4 \mathrm{~d}$ shows relatively small values of the variance (less than $2 \mathrm{~m}^{2} \mathrm{sec}^{-2}$ ) in the lower end of the updraft. Above about $7 \mathrm{~km}$, variances exceeding $14 \mathrm{~m}^{2}$ sec $^{-2}$ were observed. ${ }^{4}$

4 This was a noisy record and although values of variance exceeded $14 \mathrm{~m}^{2} \mathrm{sec}^{-2}$ by substantial amounts there is some doubt about their validity.

This suggests the growth of large, nearly dry hailstones. To a large extent, high-variance regions above $7 \mathrm{~km}$ coincided with regions of $\log \mathrm{Z}>3.5$ and with the larger volumes of rapidly rising air. One can visualize growing hailstones being carried to higher parts of the cloud. The extensions of high variances and reflectivities downwind of the updraft core suggest that the hailstones fell out of the updraft and continued to grow. 
The second, smaller region of high echo intensity at about 1555 MST is downwind of a weak updraft and is associated with a minimum in the cloud top height. Perhaps this means that during this period the radar was viewing the edge of a more intense region centered outside this height-time plane. It does not appear that any hail observed at the ground can be associated with the particular reflectivity maximum aloft at about 1555 MST. The variances observed in this region were relatively small, being less than about $4 \mathrm{~m}^{2} \sec ^{-2}$.

The fall of large hail was associated with an updraft core at about 1556 MST. It was not as well defined as the one in the early part of the period. Nevertheless, the updraft was in the form of relatively small rising volumes, within some of which speeds ranged from more than $12 \mathrm{~m} \mathrm{sec}^{-1}$ to over $20 \mathrm{~m} \mathrm{sec}^{-1}$ in the upper limits of the cloud. As would be expected, the ascending air was associated with the growth of the cloud. During the period from 1557 to 1559 MST, the average slope of the curve representing the echo top was about $11 \mathrm{~m} \mathrm{sec}^{-1}$. This is slightly smaller than the average upwards velocity of about $13 \mathrm{~m} \mathrm{sec}^{-1}$ yielded by the mean Doppler velocity (Figure 4b).

Although the reflectivity values within the broad, shaded area of $\log z \geq 4.0$ show some variation over space and time, they are small in comparison with the highly variable nature of the variance pattern. It also should be noted that at low elevations, the variance wa large after 1604 MST, but it was quite small during the preceding 4 minutes. As mentioned earlier, the reflectivity pattern suggests a continuous trail of hailstones falling from about $6 \mathrm{~km}$ to the ground. The increased reflectivity below about $4.5 \mathrm{~km}$ might be 
ascribed to a wetting of the hailstones. Battan (1971) showed that with an exponentially distributed ice-sphere population the reflectivity increases as the ice spheres become coated with water (Table 3). For distributions having maximum diameters between about 2 and $3 \mathrm{~cm}$, wetting of the ice sphere would account for increases of $\mathrm{Z}$ by more than $2 \mathrm{~dB}$ and perhaps as high as $7 \mathrm{~dB}$.

The puzzling feature of this matter is that variance values less than $4 \mathrm{~m}^{2} \mathrm{sec}^{-2}$, and without doubt those less than $2 \mathrm{~m}^{2} \mathrm{sec}^{-2}$, could not be attributed to exponentially distributed hailstones having maximum diameters greater than about $2 \mathrm{~cm}$. Variances less than about $2 \mathrm{~m}^{2} \mathrm{sec}^{-2}$ could be produced by rain or a very narrow distribution of hailstone. Values of 2 to $4 \mathrm{~m}^{2} \sec ^{-2}$ can be ascribed to the presence of a narrow distribution of large ice spheres or an exponentially distributed sample with maximum diameters between about 1 and $1.5 \mathrm{~cm}$. Therefore, it must be concluded that hailstones greater than this size, which began reaching the ground at about 1606 MST, probably did not follow the path of maximum reflectivity suggested by the pattern in Figure $4 \mathrm{a}$.

In order to explain the hail diameters larger than about $1.5 \mathrm{~cm}$, it appears to be necessary to assume that the hydrometeors had a component of motion perpendicular to the plane of observation. The horizontal distance scale was based on as assumption that the storm was moving with an average speed of $8.2 \mathrm{~m} \mathrm{sec}^{-1}$. As noted in Figure 2, the wind direction was mostly northwest throughout the cloud layer. The plane of observation 
Table 3. Calculated $\mathrm{Z}\left(\mathrm{mm}^{6} \mathrm{~m}^{-3}\right)$ for Ice Sphere Distribution $\mathrm{N}=90 \mathrm{e}^{-3} \cdot 09 \mathrm{D}\left(\mathrm{cm}^{-1} \mathrm{~m}^{-3}\right)$ When Viewed at Wavelength of $3.21 \mathrm{~cm}$. From Battan (1971).

\begin{tabular}{l|lll|ll}
\hline Maximum & \multicolumn{2}{|l|}{ Water Shell Thickness $(\mathrm{cm})$} & Ratio of $\mathrm{Z}^{\prime} \mathrm{s}$ in decibels \\
Hail Size & 0 & 0.01 & 0.05 & $\frac{\mathrm{Z}_{0.01}}{\mathrm{Z}_{0}}$ & $\frac{\mathrm{Z}_{0} .05}{\mathrm{Z}_{0}}$ \\
$(\mathrm{~cm})$ & & & & & 7.6 \\
\hline 1.89 & $3.3 \times 10^{5}$ & $5.8 \times 10^{5}$ & $1.9 \times 10^{6}$ & 2.5 & 7.1 \\
2.89 & $4.1 \times 10^{5}$ & $6.9 \times 10^{5}$ & $2.1 \times 10^{6}$ & 2.3 & \\
\hline
\end{tabular}


in Figures 1 and 4 can be regarded as being oriented northwestsoutheast. As noted in Table 2, the weather observer noted, at 1538 MST, that ground level clouds were moving rapidly from the northwest. On the other hand, at 1606 MST when the large hail began to fall, the winds at the radar were blowing very strongly from the southwest. This observation supports the suggestion that there was motion of air and hydrometeors through the observation plane.

\section{Some generalizations}

It clearly is somewhat risky to offer generalizations on the basis of the observation of two brief hail showers occurring on the same day. Nevertheless it seems worthwhile to offer some concluding remarks and indulge in some speculations.

Over the high mountain observatory on 10 August 1966 there was an unusual event for southeastern Arizona - a severe hailstorm which persisted for several hours and yielded many showers of hailstones which in some cases exceeded $2.5 \mathrm{~cm}$ in diameter. The Doppler radar observations revealed a series of short-period events, each of them lasting about 10 minutes. They occurred within convective clouds producing echo towers reaching maximum altitudes of about $12 \mathrm{~km}$. The storm consisted of a series of updraft cores which in some instances appeared to enter the cloud in the upwind side (southeast) and took a somewhat tilted path upwards through the cloud.

The updraft cores were not laminar currents but rather were composed of several large eddies having diameters of a kilometer 
or two with many smaller eddies in and around the larger ones. One has the impression of a very turbulent stream of buoyant air. The echo intensity and variance data in the lower regions of the updraft suggest the presence of only small hydrometeors. Larger hydrometeors, in some cases hail particles more than a centimeter in diameter, apparently formed in the upper parts of the updraft. As they fell into regions of weak updrafts or downdrafts, the particles continued growing.

The evidence indicates that in the upper regions of this thunderstorm there were electromagnetically dry hailstones. Furthermore it is speculated that such stones may sometimes reach several kilometers below the $0 \mathrm{C}$ isotherm before melting begins. The evidence shows that the hailstones exceeding $2 \mathrm{~cm}$ in diameter which were observed at the ground were wet.

Various investigators have proposed hailstorm models which assume a fairly smooth, quasi-steady updraft having a profile of vertical velocity which reaches a maximum at levels near or just above the $0 \mathrm{clevel}$ (Sulakvelidze, et al., 1965). It has been proposed that just above the level of updraft maximum, there is an accumulation of mostly supercooled water within which rapid hail growth occurs. The data presented in Figures 1 and 4 do not support the view of the quasi-steady updraft and the accumulation zone. Instead of a single, fairly steady updraft region, there is a series of very turbulent ones. In the upper parts of the cloud there is a distinct tendency for the regions of maximum echo intensity to be just downwind of the updraft cores. 
These data suggest that hailstone growth begins in the updraft and continues as the stones fall out of it. It is reasonable, therefore, that schemes aimed at suppressing hail damage should seek to introduce ice nuclei into the updraft in regions which are supercooled to perhaps -5 to $-10 \mathrm{C}$. In this cloud, these are not regions of high radar echo intensity and not easily identified by means of radar.

As has been observed before by others who have used Doppler. radar, the updrafts were mostly in the upper parts of the storm while the lower parts were dominated by downdrafts. Obviously, until detectable hydrometeors have come into being, there will not be a detectable echo. Therefore, the radar can not observe the early growth of a cloud when updrafts must be present. Presumably the observations of mostly downdrafts in the lower parts of thunderstorms result from observational procedures which focus on the more advanced stages of storm development.

The pattern of turbulent air motions of the kind observed in this hailstorm can account for the turbulence which is often experienced by airplanes penetrating thunderstorms. These measurements show why the character of the air motions and turbulence measured by airplanes (Musil, et al., 1973; Sinclair, 1973; and others) can vary greatly from one flight through a storm to another made at a slightly different place or time. If this storm is reasonably typical of severe hailstorms, and there are no reasons at this time for thinking otherwise, the details of the internal structure and behavior of a hailstorm 
is quite different than is depicted in most physical and mathematical models. In many studies of the growth of hailstones (e.g., Dennis and Musil, 1973; and others) it is imagined that the updraft has a smooth profile with a single maximum at some altitude above the $\mathrm{OC}$ isotherm. Growing hailstones are assumed to move through this updraft and sometimes, as proposed by Browning and Ludlam (1962), to fall out of it at high elevations and back into the same updraft at a lower elevation.

The Doppler radar observations show a turbulent updraft composed of discrete volumes which are some 1 to $2 \mathrm{~km}$ in diameter and within which there are strong upward velocities. One can visualize that growing hailstones are carried aloft within ascending volumes of cloud air. Some of the larger stones from one "bubble" may fall out of it and pass through weak updrafts or downdrafts before reaching the ground. In some cases, descending hailstones may encounter one or more upward surging volumes of air.

It seems reasonable to expect that the fastest rising volumes of air are most buoyant, having been mixed little with dry environmental air and having relatively high liquid-water contents. Rapid hail growth could occur within them. When falling through less buoyant air which presumably has mixed well with drier air, a hailstone would be expected to pass through cloud air having little supercooled water. Successive passage through a series of ascending volumes of air might account for the growth of large hailstones having alternate layers of clear and opaque ice.

The notion that assemblages of hailstones grow within fairly discrete volumes of rising air 1 to $2 \mathrm{~km}$ in diameter could account 
for bursts of hail showers reaching the ground. At a fall speed of $10 \mathrm{~m} \mathrm{sec}^{-1}$ it would take about 3 minutes to empty a vertical column $2 \mathrm{~km}$ deep. The release of hail from a series of closely spaced rising volumes of air within an updraft core might account for the well known hailstreaks. Changnon (1970), in a detailed analysis of hailstreaks in Illinois, reported that in 434 of 611 observations hail was observed at only one site in a network composed of 1 site per $8 \mathrm{~km}^{2}$. These data indicate that most hail occurs in short bursts. In cases with longer hailstreaks, it could be assumed that the hail fell from a series of closely spaced growth volumes.

In conclusion, it should be reiterated that for reasons mentioned at the outset, the one-dimensional nature of these observations makes it somewhat hazardous to offer a description of a three-dimensional phenomenon. It is essential that several hailstorms be observed with two or three scanning pulsed-Doppler radars. 


\section{REFERENCES}

Atlas, D., W. G. Harper, F. H. Ludlam and W. C. Macklin, 1960: Radar scatter by large hail. Quart. J. Roy. Meteor. Soc., $86,468-482$.

Battan, L. J., 1971: Radar attenuation by wet ice spheres. J. Appl. Meteor. , 10, 247-252.

and J. B. Theiss, 1972: Observed Doppler spectra of hail. J. Appl. Meteor., 11, 1001-1007.

Boston, R. C. and R. R. Rogers, 1969: Hail detection by Doppler radar. J.Appl. Meteor., 8, 837-840.

Browning, K. A., 1965: Some inferences about the updraft within a severe local storm. J.Atmos. Sci., 22, 669-677.

and F. H. Ludlam, 1962: Airflow in convective storms. Quart. J. Roy. Meteor. Soc. , 88, 117-135.

Bushnell, R. H., 1973: Dropsonde measurements of vertical wind in the Colorado thunderstorm of $22 \mathrm{July} 1972 . \mathrm{J}$. Appl. Meteor., 12, 1371-1374.

Changnon, S. A., Jr., 1973: Hailstreaks. J.Atmos. Sci., 27, $109-125$.

Danielson, E. F., R. Bleck and D. A. Morris, 1972: Hail growth by stochastic collection in a cumulus model. J.Atmos. Sci., 29, $135-155$. 
Dennis, A. S. and D. J. Musil, 1973: Calculations of hailstone growth and trajectories in a simple cloud model. J. Atmos. Sci. , 30, 278-288.

Donaldson, R. J., Jr., G. M. Armstrong, K. J. Banis and R. M. Dyer, 1972: Measurement of Wind Gradients in Convective Storms by Doppler Radar. Unpublished paper. Preprint Volume, Fifteenth Radar Meteor. Conf., Amer. Meteor. Soc., Boston, $22-26$.

Foote, G. B. and J. C. Fankhauser, 1973: Airflow and moisture budget beneath a northeast Colorado hailstorm. J. Appl. Meteor., 12, 1330-1353.

Hildebrand, P. H. and R. S. Sekkon, 1973: Objective Determination of the Noise Level in Doppler Spectra. Lab. for Atmos. Probing, Report No. 32, Dept. Geophys. Sci., Univ. Chicago, Chicago, Ill. $11 \mathrm{pp}$.

Ludlam, F. H., 1963: Severe local storms. Meteor. Mono., $\underline{5}, 1-30$. Marwitz, J. D., 1972: The structure and motion of severe hailstorms. J. Appl. Meteor., 11, (Part I) 166-179, (Part II) 180-188, (Part III) 189-201.

' 1973: Trajectories within the weak echo region of hailstorms. J. Appl. Meteor., 12, 1174-1182.

Musil, D. J., W. R. Sand and R. A. Schleusener, 1973: Analysis of Data from T-28 aircraft penetrations of a Colorado hailstorm. J. Appl. Meteor., 12, 1364-1370 . 
Sinclair, P. C., 1973: Severe Storm Air Velocity and Temperature Structure Deduced from Penetrating Aircraft. Unpublished Paper in Preprint Volume of Eighth Conf. on Severe Local Storms. Amer. Meteor. Soc., Boston, 25-32.

Sulakvelidze, G. K., N. Sh. Bibilashvili and V. F. Lapcheva, 1965: Formation of Precipitation and Modification of Hail Processes. Hydrometeorological Publishing House, Leningrad. (English translation in 1967 by Israel Program for Scientific Translations, 208 pp.)

Wisner, C., H. D. Orville and C. Meyers, 1972: A Numerical model of a hail-bearing cloud. J.Atmos. Sci., 29, 1160-1181. 


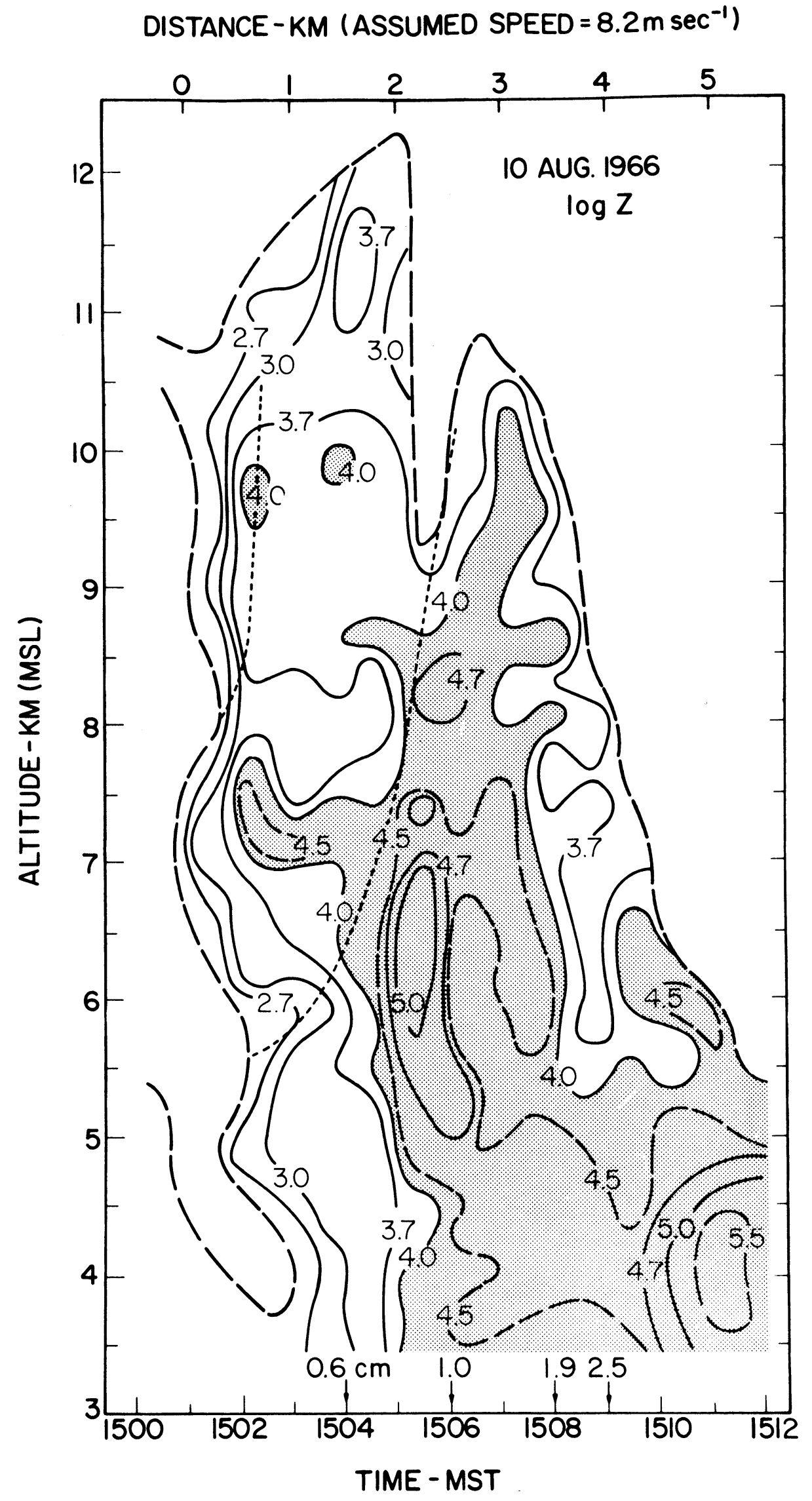

Fig. la Radar reflectivity expressed as $\log Z$ where $Z$ has units $\mathrm{mm}^{6} \mathrm{~m}^{-3}$ 
DISTANCE - KM (ASSUMED SPEED $=8.2 \mathrm{~m} \mathrm{sec}^{-1}$ )

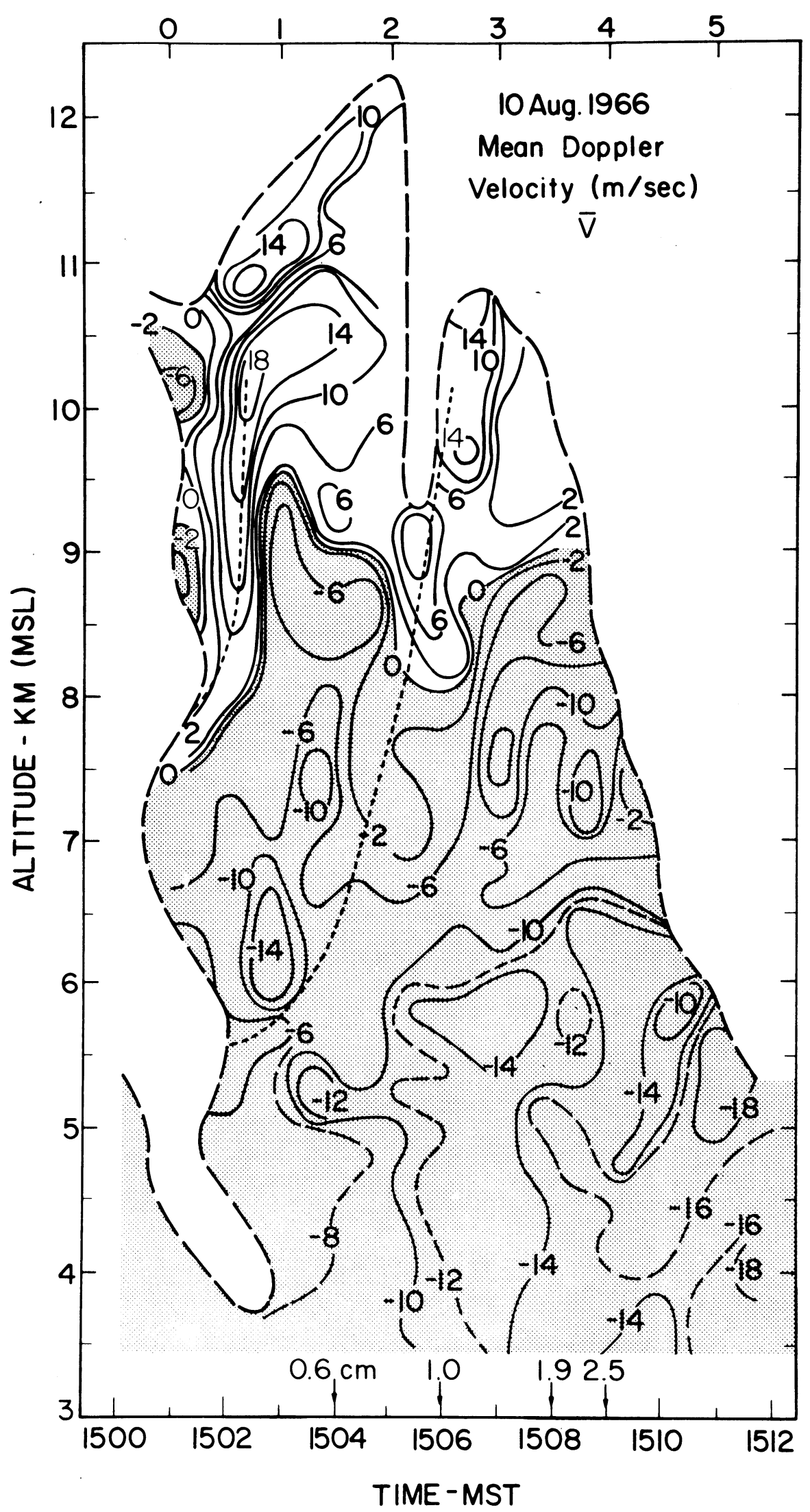

Fig. lb Mean Doppler velocity in units of $\mathrm{m} \mathrm{sec}^{-1}$ 


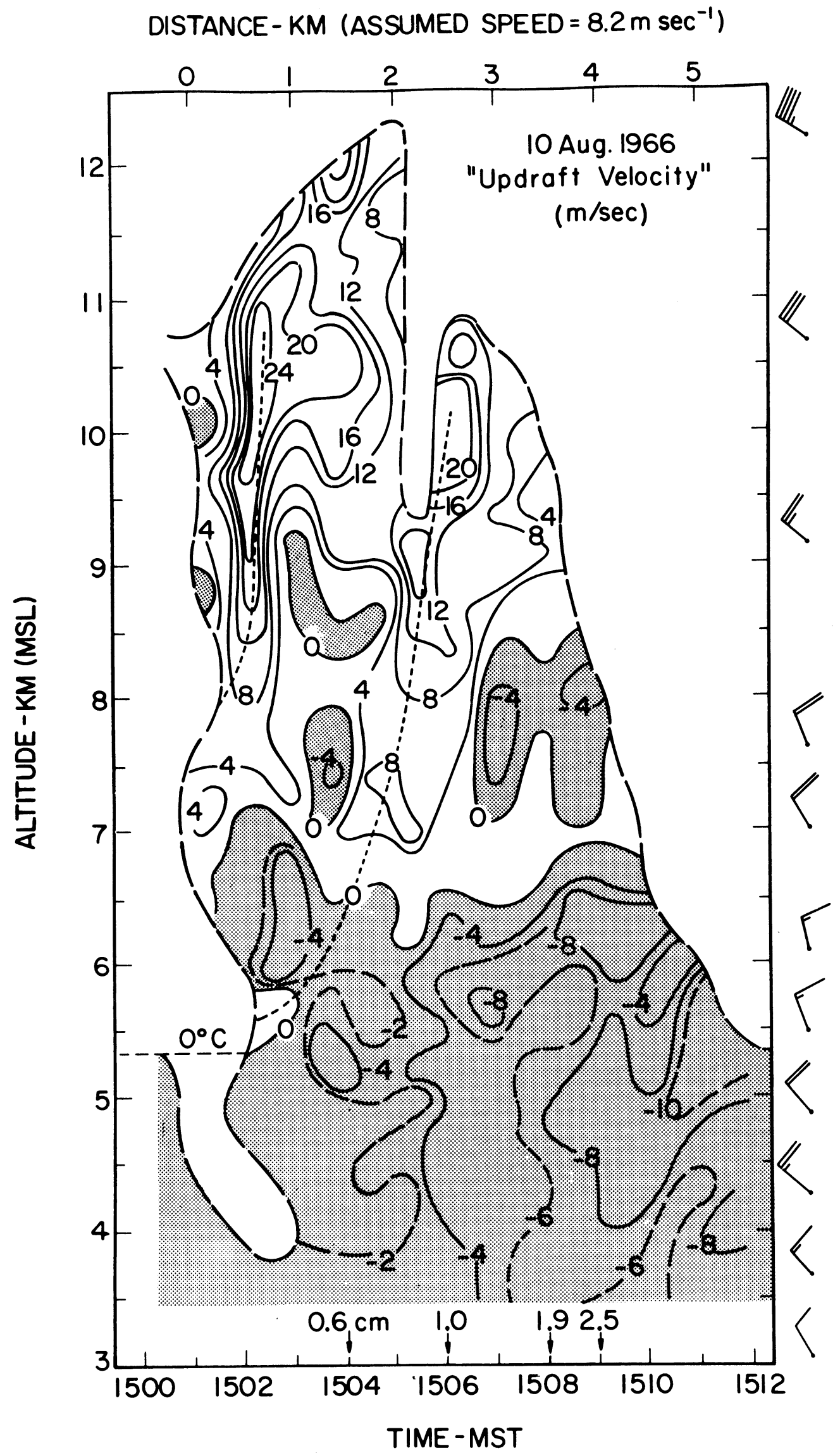

Fig. Ic An estimated updraft velocity calculated as 


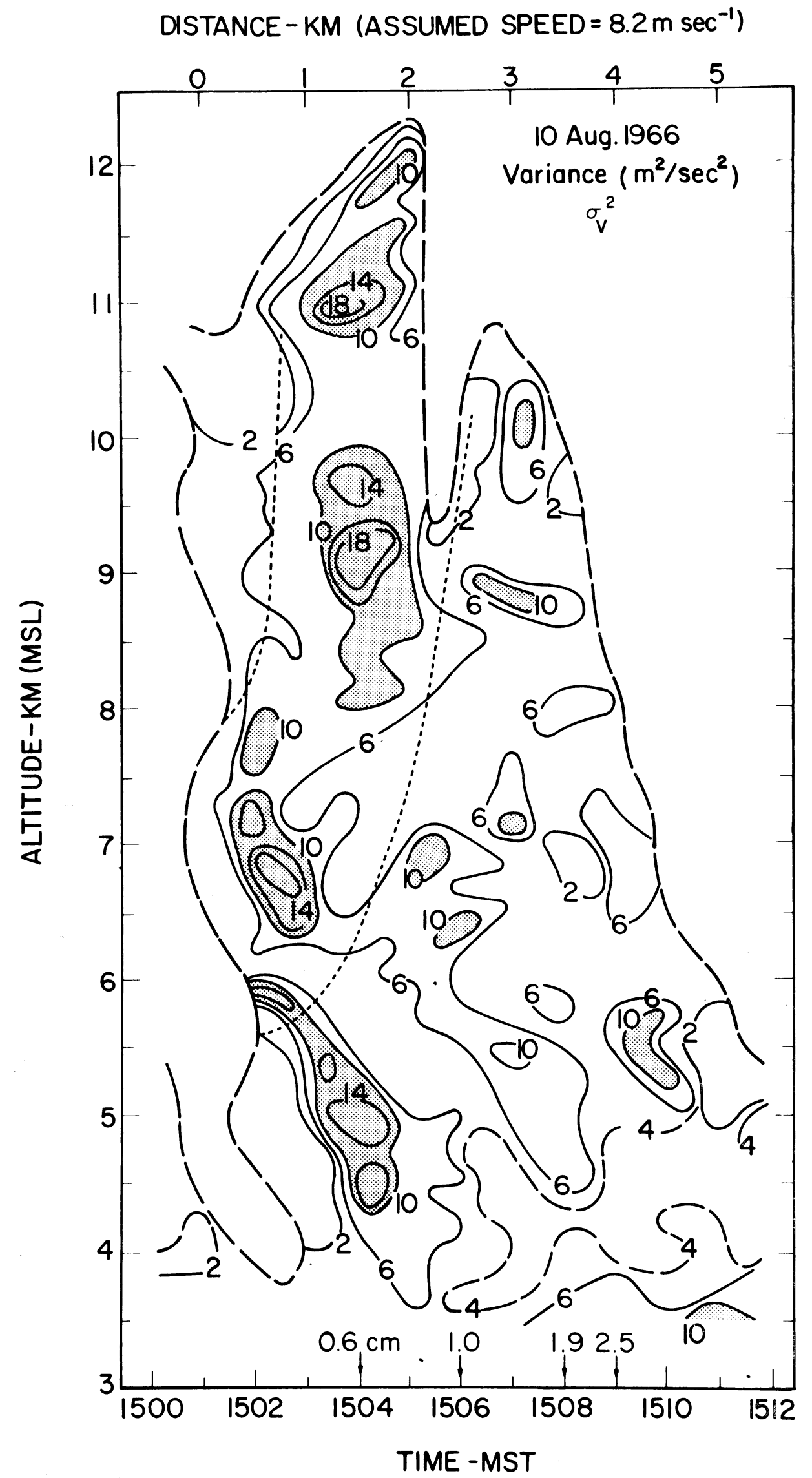

Fig. Id Variance of Doppler spectra 


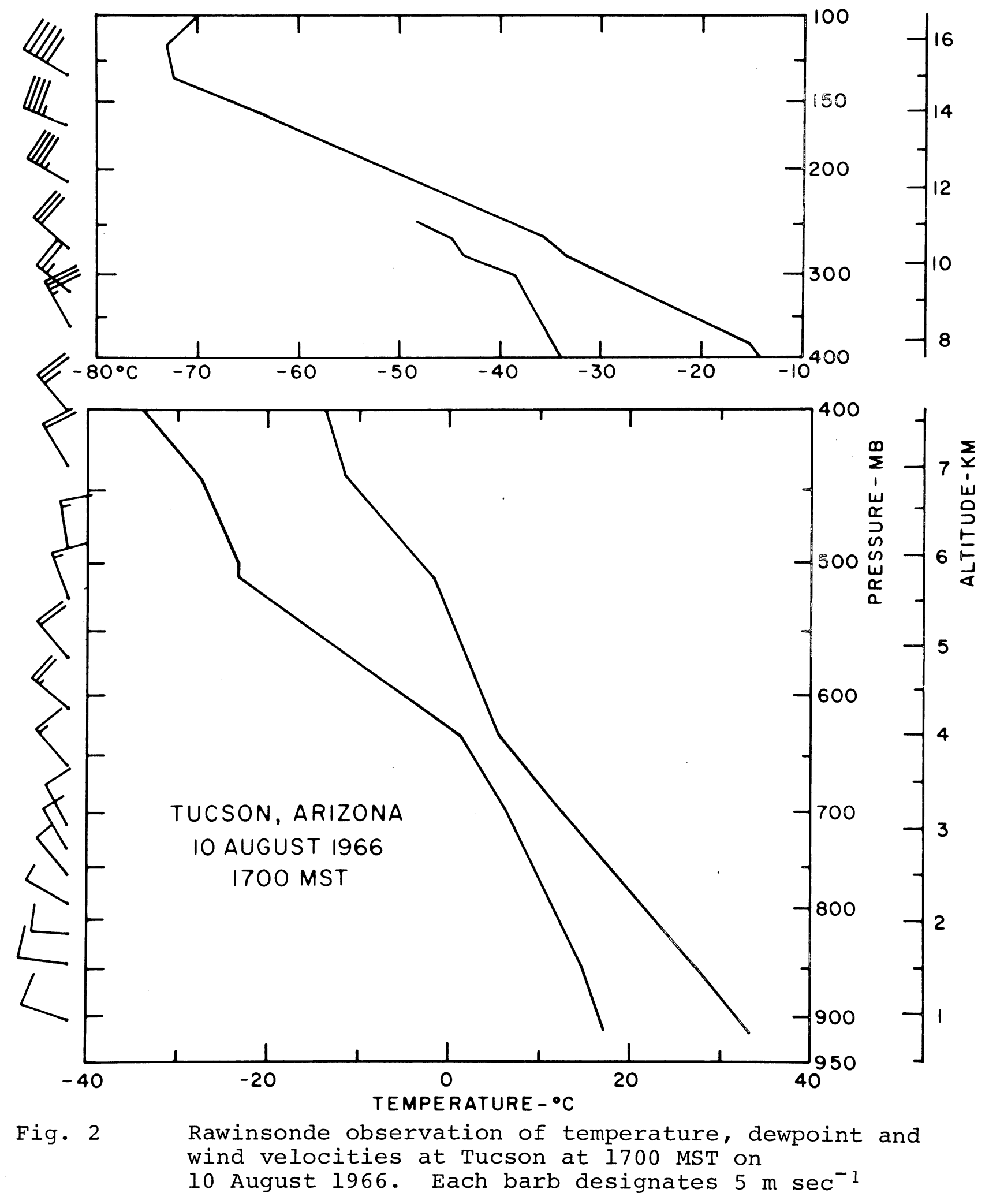




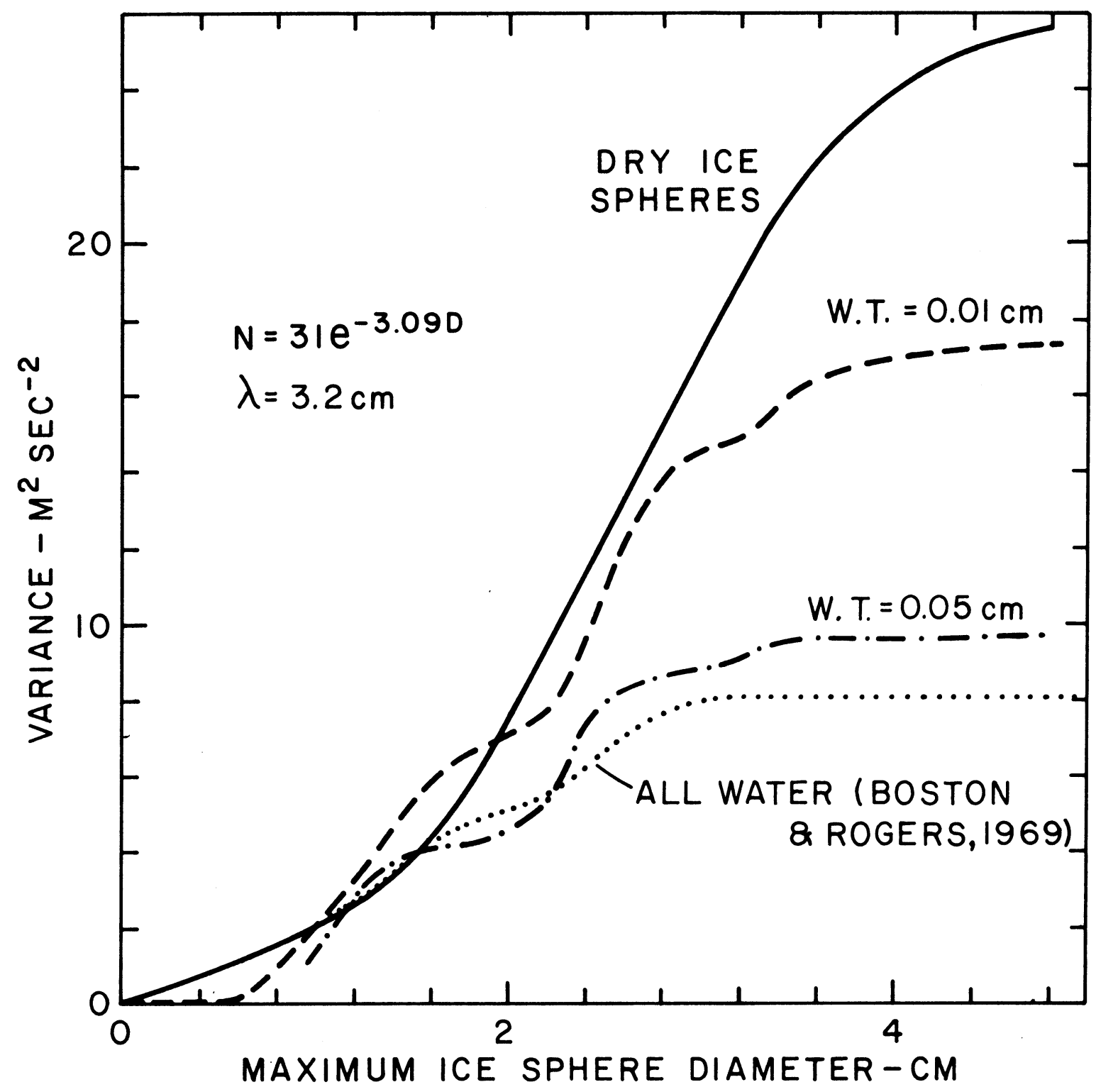

Fig. 3 Calculations of Doppler variance which would be produced by exponentially distributed dry and wet ice spheres. (Calculations by B. E. Martner, University of Arizona) 


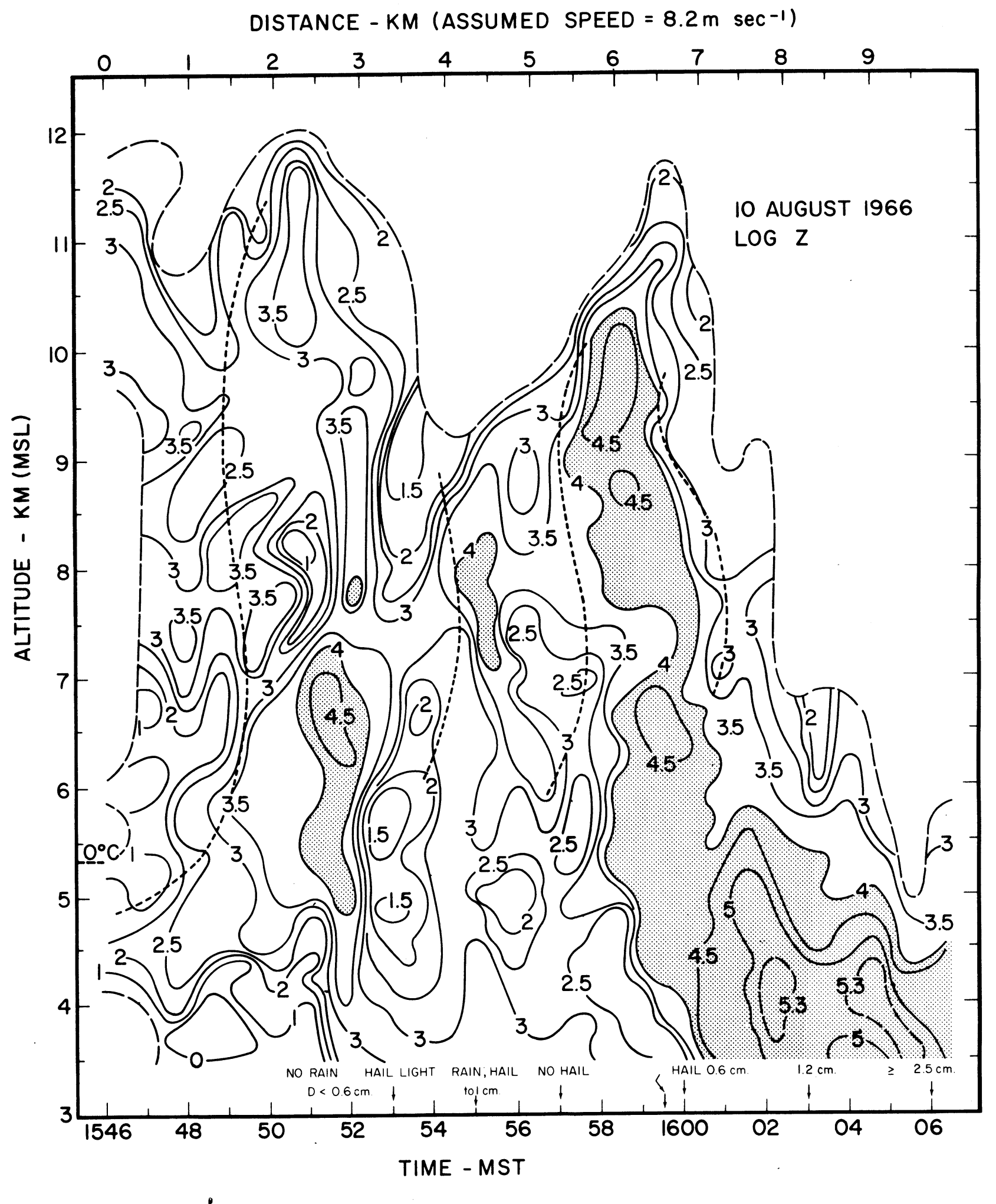

Fig. 4a Radar reflectivity expressed as $\log \mathrm{Z}$ where $\mathrm{Z}$ has units $\mathrm{mm}^{6} \mathrm{~m}^{-3}$ 


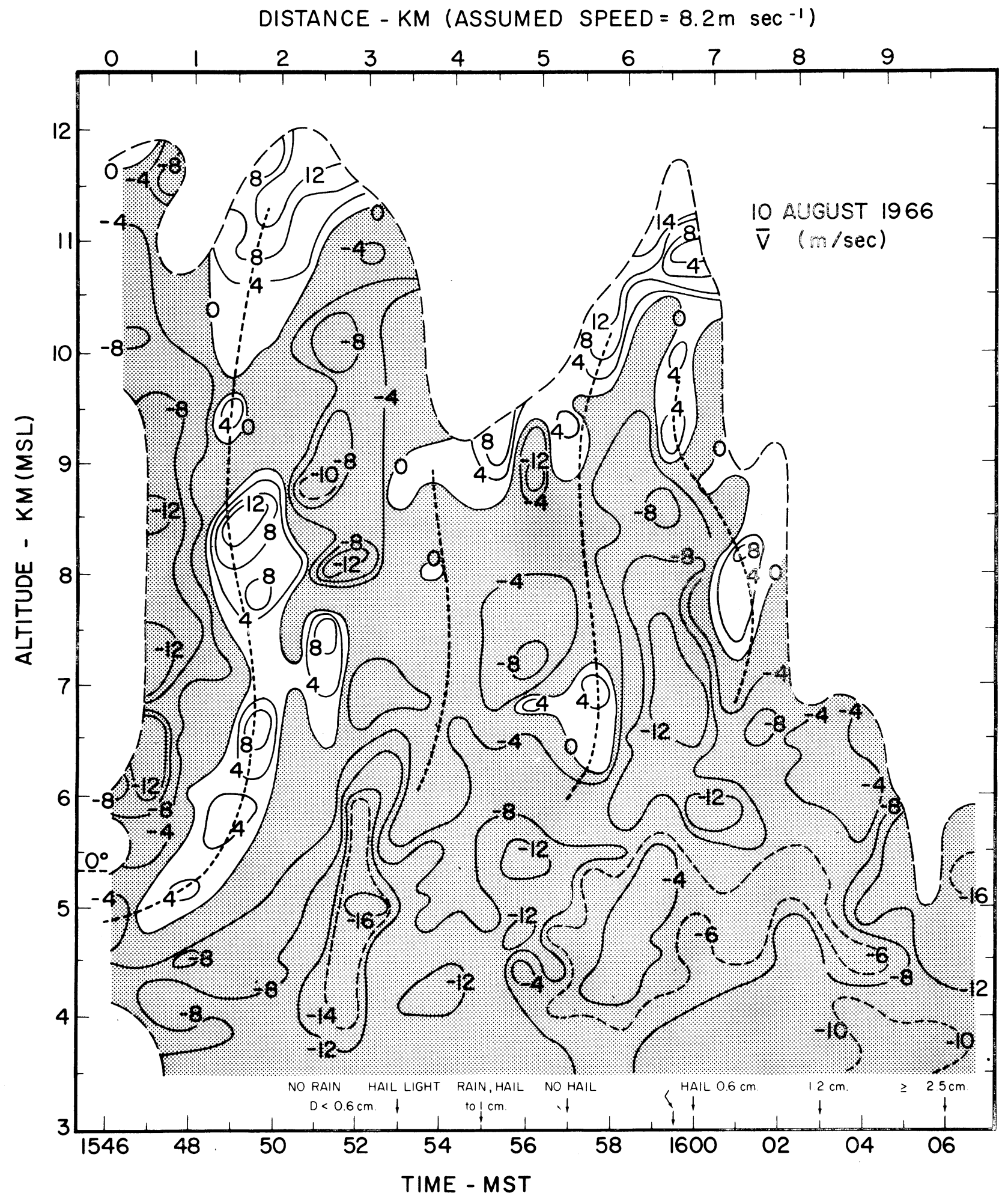

Fig. 4b Mean Doppler velocity in units of $\mathrm{m} \mathrm{sec}^{-1}$ 


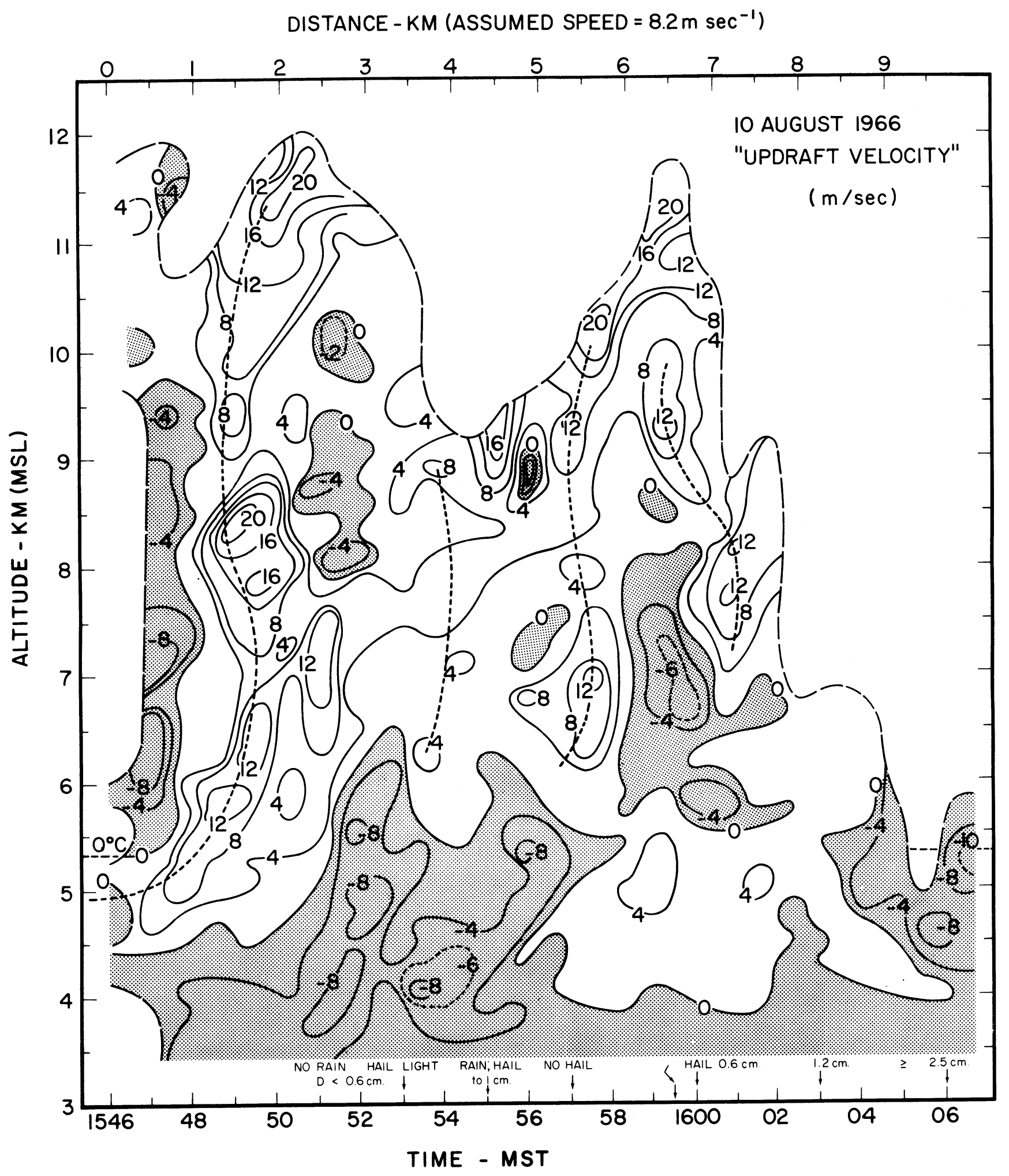

Fig. 4c An estimated updraft velocity calculated as $\mathrm{W}_{\mathrm{R}}=\overline{\mathrm{V}}+3.8 \mathrm{Z}^{0.072}$ 


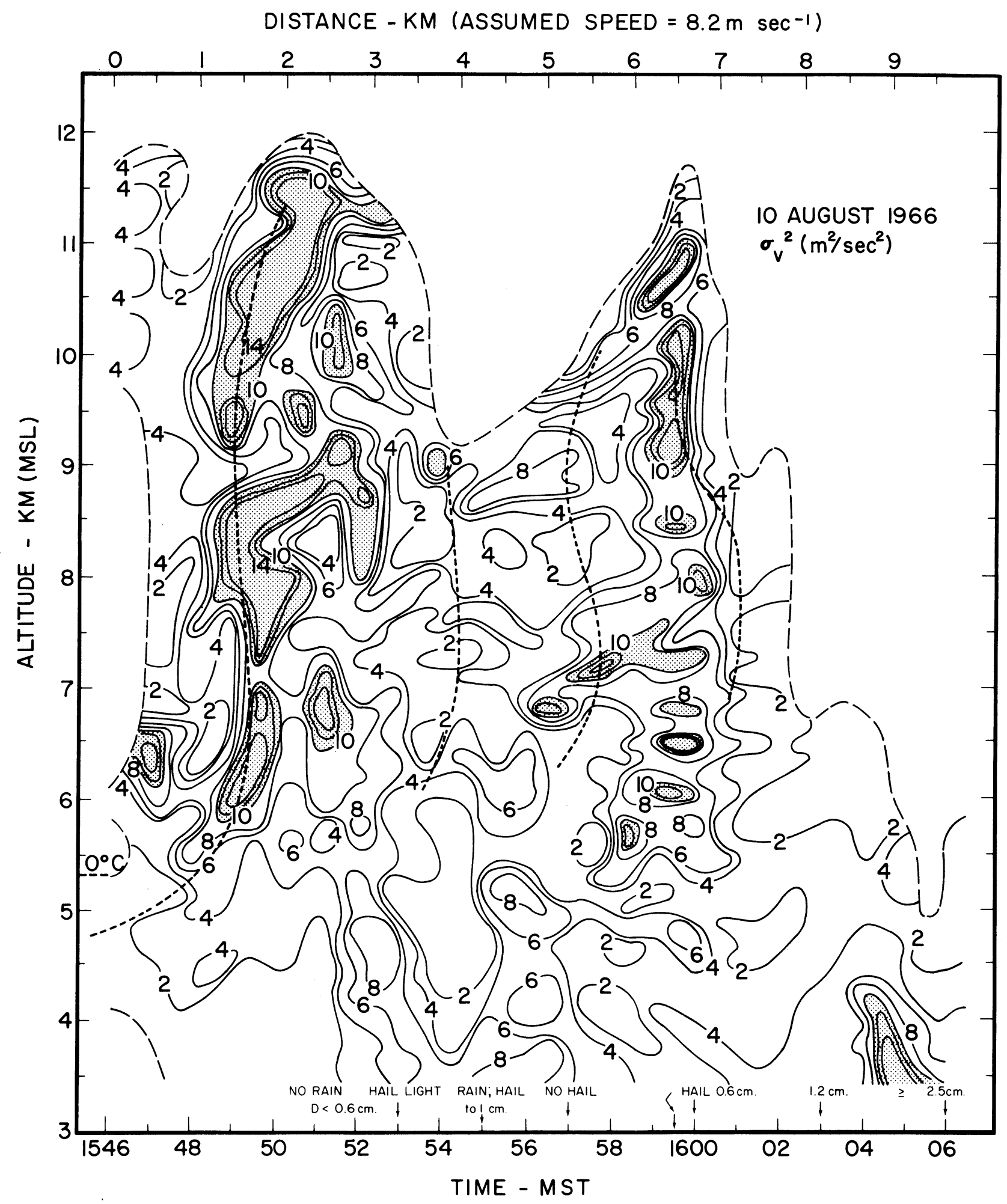

Fig. 4d Variance of Doppler spectra 